\title{
Docência no ensino superior: interpelando os sentidos e desafios dos espaços institucionais de formação
}

\section{Teaching in higher education: interpellating meanings and challenges in educational training institutional spaces}

\author{
Mara Regina Lemes De Sordi*
}

\begin{abstract}
RESUMO
O texto problematiza os sentidos e desafios dos espaços institucionais de apoio ao docente que atua no ensino superior; toma como foco o debate sobre necessidades formativas dos professores, interpelando as lógicas que as definem e que lhes emprestam direção; e, ressalta o risco de soluções neotecnicistas. O uso de narrativas é acionado como recurso revelador das tensões entre os desejos manifestos pelos docentes e as condições reais de apoio institucional oferecidas como suporte a um fazer pedagógico inovador e situado historicamente. A categoria da avaliação é recuperada em sua feição educativa para fomentar processos de reflexão verticais e criteriosos que subsidiem atuações propositivas, individuais, coletivas e institucionais, na direção de uma educação superior detentora de qualidade social construída de modo corresponsável. Advoga-se que os espaços institucionais de apoio à docência podem se tornar lugares estratégicos para fortalecimento da micropolítica dos espaços educativos de modo a sustentar o compromisso com uma formação profissional edificante sob o ponto de vista social.
\end{abstract}

Palavras-chave: Pedagogia universitária. Necessidades formativas. Desenvolvimento docente. Qualidade do ensino. Responsabilização participativa.

* Universidade Estadual de Campinas. Campinas, São Paulo, Brasil. E-mail: maradesordi14@gmail.com. https://orcid.org/0000-0003-1216-7185. 


\begin{abstract}
This texts aims to question meanings and challenges of institutional support bodies for college professors, focusing on the debate on teaching training needs and their defining and directing logics, and highlighting the risk of neotechnicistic solutions. The choice for individual narratives is used as a revealing resource of tensions between the explicit desires of professors and the real conditions of institutional support for an innovative and historical-placed pedagogical praxis. The assessment as category is retrieved as an educational aspect to encourage thorough vertical thinking processes, capable of subsidizing constructive actions, in spite of them being individual, collective or institutional, towards a co-responsible social quality higher education. It is argued that teaching support institutional spaces may become strategic places to strengthen the educational spaces micropolitics in order to commit to an uplifting professional formation within a social point of view.
\end{abstract}

Keywords: Higher education pedagogy. Training needs. Teacher development. Teaching quality. Participatory responsibility.

\title{
Introdução
}

A escassez de atenção à formação do professor universitário para o desenvolvimento de uma docência sintonizada com os desafios da contemporaneidade mobilizou estudos de pesquisadores da área e contribuiu para que se fortalecesse uma agenda institucional voltada a esses fins. Induzidos por essas demandas, avanços foram observados e já vemos com certo prazer investimentos nesta direção, na medida em que se evidencia certa disposição das Instituições de Ensino Superior (IES) em tomar como sua responsabilidade o acolhimento dos docentes ingressantes em seu quadro, destacando intencionalmente questões voltadas a um trabalho pedagógico "inovador".

Preocupa-nos, no entanto, certo viés que marca alguns programas de apoio ao desenvolvimento docente, circunscrevendo-os a aspectos de cunho tecnicista, fazendo crer que a docência de qualidade se alcança de modo instrumental, apartado dos referenciais teóricos que embasam as microdecisões pedagógicas tomadas a partir destes. Isso impõe a necessidade de interrogarmos: o que se entende por qualidade no ensino de graduação? Como têm sido desenhados os eventuais programas de apoio ao docente de modo que possam compreender e problematizar o quanto se aproximam ou se distanciam do ideário da formação humana? 
O forte apelo aos interesses mercadológicos como referencial de qualidade quase absolutizado tende a padronizar os processos formativos dos docentes de modo marcante e podem subtrair destes a complexidade que perpassa o campo da pedagogia universitária, em especial, no contexto que nos cerca. Como se constrói a legitimidade política destas propostas? A serviço de quem e do que elas se constituem e consolidam?

Este texto se estrutura em três partes: primeiramente, discutimos o esvaziamento do debate sobre os referenciais de qualidade na educação superior, que pode estar servindo ao reducionismo dos interesses mercadológicos, fluidos e efêmeros, assim como esses afetam a profissionalidade docente. Na sequência, sinalizamos os desafios vivenciados por professores iniciantes e recuperamos a reflexão sobre as necessidades formativas dos docentes atualizando-as em relação aos desafios do século 21, alertando para as ciladas do caminho deliberativo em tempos dos reformadores empresariais educacionais que têm usado as políticas avaliativas em favor dos interesses mercadológicos. Dados empíricos, que sinalizam como pensam os professores iniciantes de determinada universidade pública, captados por meio de narrativas, ajudam a iluminar as compreensões que eles têm sobre as experiências de formação e suas necessidades. Por fim, discutiremos os espaços formativos construídos para apoiar os professores, advogando que estes precisam ter foco nas necessidades sociais, posto que a sociedade espera e precisa de egressos oriundos de IES que assumam o sentido público do seu trabalho, preparando-os para uma inserção profissional, comprometida com a aplicação edificante do conhecimento, na qual não se dicotomiza know técnico e know ético. A avaliação formativa, em suas múltiplas nuances, parece contribuir para que se mantenha a vigilância sobre as escolhas e omissões pedagógicas que são feitas (no plano individual e institucional) em nome de uma qualidade educacional contestadora da lógica gerencialista e performática, comprometida com a formação humana.

\section{A educação superior e a responsabilidade na formação profissio- nal: a edificação de uma docência socialmente pertinente}

As reformas educacionais emergem no bojo das transformações produtivas que atingem o mundo do trabalho e as relações sociais, com repercussões para os processos de formação humana posto que esses cedem lugar a um discurso de competências individuais para competir no mercado. O maior objetivo é adequar 
os sistemas de ensino às regras das políticas de ajuste econômico à nova ordem mundial, dentro de um quadro de redefinição do cenário econômico internacional.

Frigotto (1996) já analisava, em estudos anteriores, os desafios na formação e profissionalização do educador, numa perspectiva de construção de relações sociais alternativas - democráticas, solidárias ou socialistas - e o papel da educação nesta construção. $\mathrm{O}$ autor enfatizava que, para responder a esses desafios, a formação e profissionalização do educador implicará dimensões ético-políticas, teóricas e político-organizativas. Observa-se que estas dimensões se afastam do perfil profissional induzido pelas políticas de regulação vigentes, exacerbando as repercussões nefastas sobre o projeto de formação humana que deve presidir a formação profissional emprestando-lhe direção e intencionalidade.

Isso posto, temos que considerar que os tempos atuais exigem tomada de posição clara quando se pensa sobre a formação de professores em geral e em particular a dos professores universitários.

Sob a perspectiva das atuais políticas de regulação da qualidade da escola pública, a desqualificação do trabalho dos professores é gritante e se admite que este pode ser formado de modo aligeirado e precário, pautado no neotecnicismo, tornando-os ávidos consumidores de receitas prescritivas sobre o jeito certo de se ensinar, quase sempre desprovidas de reflexão sobre os desdobramentos dele originários.

Se este cenário afeta a pedagogia em geral, no campo da pedagogia universitária os conflitos se ampliam posto que boa parte dos professores universitários têm se mantido afastados dos saberes pedagógicos necessários para a consecução de seu trabalho docente e desestimulados a se embrenharem ativamente neste estudo, que ganha relevância na medida em que velhos modelos de ensino se mostram defasados em relação ao perfil de estudantes que frequentam os espaços universitários, defasados em relação aos desafios impostos pela sociedade do conhecimento e defasados em relação aos valores que precisam, mais do que nunca, presidir as atividades formativas desenvolvidas nos diferentes cenários de aprendizagem. Sem que o campo da pedagogia universitária tenha se firmado indelevelmente, as atuais políticas de avaliação que incidem sobre as universidades conspiram para uma pedagogia universitária mais rasa e neotecnicista, na qual os fins cedem importância aos meios. Acresce-se a este cenário a baixa relevância atribuída ao ensino de graduação que concorre em desvantagem com políticas avaliatórias que prezam mais a pesquisa e acabam por direcionar as energias dos docentes ingressantes.

Esta lógica precisa ser contestada. As instituições de educação superior estão convocadas a repensar que tipo de cidadão querem formar e a esclarecerem em que aspectos a inserção de seus egressos no mundo do trabalho pode ajudar a reconfigurar o tecido social em que estamos vivendo. 
Enveredar pelo caminho da contrarregulação (FREITAS et al., 2009) implica defesa intransigente de uma formação de professores que se confronte com esse perfil. Trata-se de intensificar aprendizagens que expressem valores capazes de dar sentido à educação escolarizada. O processo de formação do educador precisa ser reconfigurado de modo mais amplo, crítico, rigoroso, afastando-se de aprendizagens meramente instrumentais voltadas ao ensino do que cai nas avaliações externas ou aquilo que se encaixa pragmaticamente ao que o mercado demanda.

Visto sob qualquer ângulo, o terreno da mudança e das reformas em educação não pertencem ao domínio do técnico, da utilização de métodos ativos de ensino, do uso acrítico das tecnologias; da reestruturação do currículo. Antes de mais, trata-se de um âmbito de nossa realidade social, cultural e educativa em que nos questionamos sobre que tipo de sociedade e cidadãos queremos, que tipo de escola, que tipo de professores/profissionais e, por isso mesmo, temos que esclarecer, argumentar e legitimar os valores subjacentes a tudo isso.

Uma reforma sem valores e ideologias ou, dito de outro modo, com valores e ideologias que não promovam os valores mais genuínos da democracia, será, posteriormente, uma forma de tecnocracia, mais ou menos dissimulada mas, no fundo, uma forma de regulação e controle social de uns sobre os outros, de interesses à expensas de outros alternativos, do conhecimento e da cultura hegemônica à custa do conhecimento e da cultura marginal (ESCUDERO; BOTIA, 1994, p. 106).

Advertem ainda Escudero e Botia (1994, p. 108) que "a mudança educativa não pertence ao domínio das certezas técnicas, mas ao âmbito humano da indeterminação, da imprevisibilidade, da conflituosidade de opções morais".

Se admitirmos a complexidade e nebulosidade da situação que afeta as reformas educacionais, cabe nos colocar em estado de alerta de modo a evitarmos encaminhamentos ingênuos ou heróicos. Importante, ainda, refletir sobre a complementariedade entre os protagonismos de ordem individual e coletiva para potencializar os processos de mudança na universidade e este princípio precisa ser fortemente ativado, tanto nos processos de formação inicial como na educação permanente dos profissionais da educação. Escudero e Botia (1994, p. 109), destacam que 
A insistência na necessidade da conformação social e colegial da melhoria escolar não deve conduzir, de modo simplificado, a obviar a dimensão irremediavelmente pessoal que é necessária para criar e realizar a mudança nas práticas educativas de professores e alunos.

Assim, cresce a legitimidade da criação de espaços de formação e apoio ao trabalho docente dos docentes universitários que promovam a edificação de uma docência socialmente pertinente. Cresce o sentido de exercermos nossos protagonismos, individual e coletivo, para enfrentarmos um cenário nebuloso no qual se mudam as narrativas sobre qualidade educacional na educação superior enquanto os processos decisórios se concentram nos paradigmas criticados como defasados. Um exame acurado sobre as necessidades formativas requeridas pelos docentes universitários se torna premente. Avaliar estas questões parece ser crucial para que soluções mais robustas possam ser acionadas ajudando os professores iniciantes e/ou ingressantes em universidades públicas a não se furtarem de seu compromisso com a sociedade.

\section{A propósito das necessidades formativas: um olhar sobre o profes- sor iniciante}

Nunca foi simples assumir o papel de professor universitário e a complexidade desta função só tem feito crescer. A roda viva da universidade constrange as possibilidades de uma aprendizagem da docência menos sofrida e mais situada socialmente.

O professor universitário, ao ingressar na carreira docente em uma instituição de ensino superior, vivencia uma fase de "sobrevivência" e "descoberta" (HUBERMAN, 1992) ou, ainda, um momento de socialização (MARCELO GARCIA, 1999). Além do contato com a cultura institucional (à qual precisa se ambientar), com as atividades de pesquisa e extensão, enfrenta inúmeros desafios para desenvolver a atividade de ensino, tendo em vista que sua trajetória de formação, nos cursos de graduação e pós-graduação, está vinculada à aquisição de conhecimentos específicos de sua área de atuação profissional, sobretudo os graduados em cursos de bacharelado que, no Brasil, não habilitam para o exercício da docência.

Algumas investigações sobre os desafios, dilemas, dificuldades e tensões vivenciadas no período de iniciação à docência apontam para a necessidade de 
apoio institucional ao professor iniciante, destacando a importância de ações de formação pedagógica, de acolhida e/ou de acompanhamento (GONÇALLO, 2017; WIEBUSCH, 2016; HEES, 2016; SILVA, 2015; ROSA, 2015; ENGEL, 2014; COELHO, 2009).

Destacamos, por exemplo, a tese de Silva (2015), que objetivou compreender o processo de construção de professores iniciantes na docência universitária, mediatizados por movimentos e experiências no cotidiano de suas práticas. As entrevistas narrativas com professores de uma universidade pública evidenciaram que as expressões "choque com a realidade"; "solidão pedagógica"; "aterrissa como podes"; "nada ou afunda-te" caracterizam o vivido pelos professores nos anos iniciais na universidade, pois não encontraram acolhimento de forma sistematizada, com apoio institucional. Silva (2015, p. 164-165) conclui que:

\begin{abstract}
Na dinamicidade da prática docente, os professores estão se construindo de forma singular, se refazendo e configurando uma identidade própria de ser professor. Entretanto, a fragilidade da formação para a docência e a insipiência do apoio institucional no ambiente acadêmico retarda e afeta a construção da profissionalidade, que se situa mais numa responsabilidade individual, do que como parte das políticas públicas que sustentam a expansão da educação superior pública no país.
\end{abstract}

Nessa perspectiva da responsabilidade institucional, alguns trabalhos têm direcionado o seu olhar para as experiências de formação do professor iniciante, sobretudo nas universidades espanholas (MAYOR RUIZ, 2009; MAYOR RUIZ; SÁNCHEZ MORENO, 2000; FEIXAS, 2002; FONDÓN; MADERO; SARMIENTO, 2010). No contexto brasileiro, Zanchet et al. (2012) destacam que as instituições de ensino superior, em geral, ainda não se mobilizam sistematicamente para o apoio e acolhimento do professor iniciante. Segundo os autores, "em alguns casos tem alguma orientação inicial, o que se distancia em muito de um processo sistemático de formação para o exercício da docência universitária" (p. 155).

Bozu (2009) aponta que a existência dos programas de indução pode ajudar os professores a enfrentar de modo mais efetivo a profissão, funcionando como mecanismos práticos da etapa de socialização. Para a autora, a concepção e implementação de um programa de formação inicial para a docência devem partir da revisão bibliográfica e passar tanto pela identificação das necessidades de formação quanto pelos problemas que preocupam os professores iniciantes. E destaca a necessidade do reconhecimento desse processo formativo, seja pelos 
professores seja pela gestão universitária (institucionalização da formação), colaborando na profissionalização da docência na universidade.

Nessa perspectiva, compreendendo a necessidade de apoio institucional aos professores universitários, diante dos desafios vivenciados no período de iniciação à docência, destacamos a relevância do debate sobre necessidades formativas.

Segundo Rodrigues e Esteves (1993), nas ações de formação, a análise de necessidades pode contribuir na definição de objetivos e decisões sobre conteúdos e estratégias. É um instrumento menos técnico e mais pedagógico, que considera o conhecimento dos interesses, expectativas e problemas enfrentados pelos docentes. E que desempenha uma função social, considerando as necessidades socialmente detectadas.

Lima (2015), a partir de um levantamento das dificuldades sentidas por professores iniciantes em uma universidade pública, analisou como se configuram as suas necessidades formativas (dimensão objetiva e subjetiva), tendo em vista a construção de um programa de formação continuada, a partir dos temas de interesse. Segundo a autora, "[...] há que se problematizar a diferença entre a percepção (subjetiva, portanto) das necessidades de formação por parte dos docentes, cotejando-as com as postas pela universidade e pelo mundo atual e futuro" (p. 357). Portanto, para além da dimensão técnica, que prevalece na percepção dos participantes, outras dimensões são importantes, como a cultural, a ética, a estética, a tecnológica e a ambiental (LIMA, 2015).

Destacamos o trabalho de Benedito, Imbernón e Félez (2001), que realizaram uma investigação sobre as necessidades de formação de professores iniciantes da Universidade de Barcelona. Os autores sinalizam que é conveniente que se elaborem propostas de formação a partir do conhecimento dessas necessidades. Reconhecendo a polissemia do conceito de necessidade e as diferentes formas de compreender as necessidades no campo da formação, sustentam-se em uma perspectiva dupla e dialética do conceito de "necessidade de formação", que guiou todo o processo de coleta (quantitativa e qualitativa) e análise, buscando um equilíbrio entre a necessidade prescrita (determinada) e a sentida (manifestada).

A gênese desta questão está em esclarecer sob qual concepção de qualidade identificaremos as necessidades formativas do professor universitário. Serão estas advindas dos requerimentos do mercado e que assim definem um perfil de profissional a ser formado de cunho mais utilitarista, pragmático? Que tipo de docência é necessário para atender a este perfil? Que necessidades formativas se inscrevem no imaginário do docente e ou da instituição? Quem comanda quem neste caso?

Se a concepção de qualidade que subjaz esta questão for o entendimento 
de que a formação humana é que deve inspirar a matriz curricular dos cursos bem como as microdecisões do currículo em ação e oculto, forçosamente, a reflexão sobre as necessidades formativas do docente para engendrar este perfil de profissional se alteram substantivamente. Tenha ele esta percepção ou não.

A inversão na ordem das coisas e das prioridades neste caso faz toda a diferença. Ou seja, o que determina a lógica da formação do professor universitário para a docência na graduação? A resposta dada a esta questão nos informará sobre os valores que estão sendo realçados ou subestimados pelas políticas institucionais. A avaliação da qualidade do projeto formativo abstratamente definida deixará obscuras as questões que se seguem, entre outras:

O projeto educativo a que a IES está filiada e o alinhamento de suas políticas locais a determinado projeto histórico;

A postura diante dos resultados da avaliação externa sustentada pela coerência dos princípios do projeto educativo: autonomia responsável ou social conformismo (SOUSA SANTOS, 2008);

O cuidado institucional com as políticas que regem o ensino de graduação e o lugar que ocupa em relação à Pós-graduação;

A sustentabilidade financeira dos processos inovadores da tríade ensinar/ aprender/avaliar inscrita no Plano de Desenvolvimento Institucional (PDI) e que dão concretude ao discurso institucional sobre qualidade;

As formas de enfrentamento institucional levadas a cabo ante a heterogeneidade dos seus estudantes no que toca ao capital social, econômico, cultural que trazem para os cursos;

A leitura que os gestores institucionais fazem do uso das tecnologias da comunicação e informação como recurso ou fim;

A robustez das políticas institucionais de apoio pedagógico oferecidas aos docentes iniciantes e ou ingressantes que incluem o enfrentamento da espinhosa questão sobre a gestão dos tempos e espaços para que a formação do docente aconteça.

Parece consensual que a sociedade do conhecimento não combina com um professor que ensine com lógicas do passado e que sonegue aos estudantes o direito de aprender pensando, ativamente e com criticidade social.

O professor vê-se numa emergência de construção de novos saberes, tendo em vista que os conhecimentos que davam sustentação a um ensino prescritivo e legitimado pelo conhecimento científico, mostram-se insuficientes devido à complexidade que compõe o cenário macroestrutural (RIVAS; CONTE; AGUILAR, 2007, p. 6). 
Se este cenário impõe novos desafios ao docente, não será surpresa imaginar que as IES, já implicadas com a formação pedagógica de seus profissionais/ professores, devam ser instadas a repensarem e ou reinventarem suas peculiares formas de apoio aos docentes, tanto ingressantes como já vinculados há mais tempo. Lima (2015) nos adverte sobre a polissemia do termo "necessidades" quando a questão invade a esfera da formação docente. Se necessidade é algo que indica uma carência em relação a determinado referente, toca-nos problematizar:

Professores manifestam necessidades a partir do quê? Curiosidades no campo da docência, interesses pessoais por determinados temas, respostas a queixas/demandas alunos, modismos, carências derivadas da mudança paradigmática em curso?

Gestores planejam ações de apoio pedagógico em função das demandas de docentes unilateralmente afirmadas ou tencionam a ambiguidade existente entre necessidades desejadas e necessidades ainda não desejadas porque sequer conhecidas pelos docentes? Assumem proativamente seu protagonismo político no projeto institucional induzindo mudanças e criando atmosfera favorável ao surgimento de novas demandas, ainda não sentidas pelos docentes como desejáveis e necessárias?

Nesse sentido, Benedito, Imbernón e Félez (2001) indicam que as necessidades, tal como são sentidas e expressas pelos professores, têm, sim, de ser consideradas, porém não em termos absolutos. Assentam essa indicação nas seguintes questões:

Se um grupo de docentes novos não utiliza, por exemplo, recursos audiovisuais nem tampouco os exige, devemos interpretar que não necessitam deles? Mas como poderiam requerer certo tipo de formação no uso desses recursos se os desconhecerem ou não tiverem os conhecimentos adequados para fazê-lo? A formação do professorado novo, então, deve responder unicamente às suas demandas pessoais ou deve acrescentar também certos critérios institucionais e/ou econômicos? (p. 3).

A complexidade cresce quando observamos que dada a rarefação dos tempos de reflexão e deliberação conjuntos, podemos sucumbir ao imediatismo e engendrar propostas que desconheçam o quanto alguns profissionais/professores estão afastados do entendimento do que seja uma formação humana, maiúscula, em tempos sociais que exigem um novo olhar, garantidor de uma 
ciência prudente, edificante para uma sociedade eticamente decente (SOUSA SANTOS, 2008).

Não se trata mais de apostar em cursos exclusivamente preocupados com a instrumentalização do docente para um agir pedagógico moderno, capaz de mobilizar a atenção dos estudantes, mas de planejar e implementar ações formativas que transitem, tanto no âmbito dos interesses individuais como dos interesses institucionais, com primazia destes últimos. $\mathrm{O}$ foco é desnudar o risco presente quando contraditoriamente as IES apelam para narrativas inovadoras na forma de ensinar muito embora se alinhem com posturas conservadoras ao anunciarem o sentido da formação universitária que veiculam ou o caráter coadjuvante que o ensino ocupa dentro da política institucional.

As narrativas (escritas/orais) de docentes iniciantes de uma universidade pública, elaboradas no âmbito de uma pesquisa, nos auxilia na compreensão de como o apoio institucional influencia a ressignificação das decisões pedagógicas assumidas no trabalho desenvolvido no ensino de graduação, no que se refere à compreensão da dimensão do planejamento de disciplina, da aproximação com a metodologia ativa de ensino, bem como na construção de novos sentidos para o processo de avaliação da aprendizagem.

Para um professor da área de Exatas, por exemplo, a experiência institucional de formação "revolucionou vários conceitos" seus em relação ao ensino, sendo que "foi muito interessante aprender diversos conceitos de pedagogia para poder planejar um curso de graduação". O professor reflete, em sua narrativa escrita: "Não acho que seja fácil aplicar todos os conceitos vistos, até porque precisamos abrir mão de muita coisa que vemos nossos professores fazerem durante a vida".

Outra professora, da área da Saúde, que também vivenciou a mesma experiência, destaca em sua narrativa escrita:

"Com esses conhecimentos percebi que com planejamento e abordagem ativa das aulas, saindo da aula tradicional expositiva, a prática da docência fica mais agradável e com melhores resultados para o professor e para os alunos principalmente."

Alguns professores reconhecem a importância dessas ações, porém indicam as dificuldades para participar, considerando as demandas do trabalho docente. $\mathrm{Na}$ visão de uma professora da área de Exatas:

[...] tem que ter uma hora onde seja necessário que o professor participe de um processo de reflexão, de aprender novas técnicas, porque o tamanho da carga horária que a gente tem é muito grande. 
Certamente, as ações institucionais de formação podem ir ao encontro das necessidades sentidas pelos professores universitários bacharéis, sobretudo se considerarmos que, em suas trajetórias de formação acadêmica, tiveram poucos contatos com os conhecimentos necessários ao exercício profissional da docência. Porém, percebemos que suas narrativas revelam, regularmente, uma compreensão restrita à dimensão técnica do fazer pedagógico, na busca por caminhos inovadores que, muitas vezes, podem não contribuir para o contexto específico no qual eles se inserem.

Isso implica no desafio de assunção de um projeto institucional que potencialize os processos de reflexão crítica e consciente sobre a realidade de atuação profissional, na micropolítica dos espaços educativos, a partir de uma articulação permanente entre o saber e o fazer. Essa perspectiva contribui para a sustentação de uma inovação edificante, no reconhecimento do professor como agente de transformação social (VEIGA, 2009), bem como considera a relevância do compromisso e implicação com o perfil dos egressos dos cursos na perspectiva da qualidade social.

No seio desse desafio, as ações de avaliação podem contribuir para a compreensão das necessidades sentidas pelos professores, bem como para o desencadeamento de processos de reflexão, sobretudo se considerarmos, a partir do contexto investigado, o reconhecimento que os professores expressam, em suas narrativas, do olhar do outro sobre o trabalho que desenvolvem e da ressignificação das ações de avaliação.

Se, por exemplo, considerarmos as ações conduzidas pelas unidades acadêmicas, identificamos algumas limitações. Para uma professora da área de Exatas, em sua narrativa oral:

[...] o que eu vejo dessas reuniões de avaliação de curso, que tá em andamento, não tem retorno. São as mesmas reclamações, professor reclama de aluno, aluno reclama de professor e não mexe, não muda.

Considerando essas ações, um professor da área de Exatas manifesta sua expectativa na narrativa oral:

[...] o que eu gostaria é que a gente tivesse uma avaliação de disciplina que pudesse efetivamente dar um feedback ao professor sobre o que efetivamente ele fez de bom e de ruim, e como poderia melhorar. E que isso fosse levado a sério, que isso depois fosse efetivamente usado pelo professor pra melhorar o curso [...] Então tem que criar um banco de dados de sugestões e melhorias. Ou 
criar um manual de boas práticas, algo do gênero, para os professores seguirem. Acho que é isso que eu esperaria de uma avaliação bem feita.

Além da expectativa pela efetividade das ações de avaliação, os professores sentem necessidade do olhar do outro sobre o trabalho que desenvolvem. Para uma professora da área de Exatas:

[...] você tá muito sozinho nessa empreitada de ser professor.

Porém, alguns professores têm dialogado com seus pares, iniciantes ou veteranos, ainda que reconheçam algumas limitações para o fortalecimento desse diálogo. Segundo uma professora da área da Saúde:

[...] eu tenho uma colega que é recente, que já deu aula em outra universidade, mas que ela entrou junto comigo e a gente troca algumas ideias também sobre o que seria legal de fazer [...] a gente ficou bem motivada pelo encontro de novos docentes e foi ali que eu tive várias ideias. Mas aí depois disso não tem muita gente que eu converso não. Eu vou tentando fazer na minha, o meu feeling. Eu inclusive devia buscar mais fontes.

Uma avaliação que desencadeie processos de reflexão pode se consolidar na medida em que existe o reconhecimento dos professores sobre a necessidade de reflexão, a exemplo de um professor da área de Artes, que destaca em sua narrativa oral:

[...] preciso parar um pouco para dar uma revisada nas coisas que eu tenho feito [...] não estou fazendo como eu gostaria de fazer, com um pouco mais de tempo pra reflexão, pra revisão.

Já para uma professora da área de Exatas:

[...] alguma coisa certa eu estou fazendo. Não sei muito bem o quê que é [...] eu não estou colhendo dados, não estou sabendo exatamente, não estou me observando, eu não me observo. Então eu não sei exatamente onde eu estou fazendo a coisa certa [...] queria adquirir mais essa base, porque existe conhecimento, o conhecimento tá lá, ele já foi publicado, foi discutido por " $n$ " autores, eu queria acessar esse conhecimento, eu queria ter um tempo, queria ter uma interface de dar e acessar esse conhecimento. 
Compreendemos, assim, a necessidade de espaços de formação que possibilitem a reflexão sobre os desafios vivenciados no contexto do exercício profissional da docência, considerando não só os conhecimentos pedagógicos necessários, como também a articulação com o projeto de formação universitária almejada.

\title{
Legitimidade dos espaços de formação pedagógica no contexto universitário e a indissociável relação com a formação humana do profissional do século 21
}

Cunha (2008) tem insistido na discussão que diferencia espaço/lugar e território de formação. Como já anunciamos tem crescido a criação de espaços de formação pedagógica institucionalizados. O desafio é transformá-los em lugares de formação.

\begin{abstract}
A dimensão humana é que pode transformar o espaço em lugar. O lugar se constitui quando atribuímos sentido aos espaços, ou seja, reconhecemos a sua legitimidade para localizar ações, expectativas, esperanças e possibilidades. Quando se diz "esse é o lugar de", extrapolamos a condição de espaço e atribuímos um sentido cultural, subjetivo e muito próprio ao exercício de tal localização. Minha gaveta pessoal de pertences é um espaço; porém, quando coloco minhas coisas e reconheço a propriedade dessa organização, defino um lugar (CUNHA, 2008, p. 184).
\end{abstract}

Nesta perspectiva, as IES podem avançar criando espaços de formação pedagógica, que devem ser celebrados como condição necessária, mas insuficiente para os fins que se postula. Precisam ser guinados à condição de lugar. O lugar, então, é o espaço preenchido, não desordenadamente, mas a partir dos significados de quem o ocupa. Nem sempre os espaços de formação dos docentes da educação superior são ocupados e, por essa razão, não se transformam em lugares (CUNHA, 2008). Sua legitimidade técnica e política sofrem fissuras. Os professores precisam ocupar e dar vida aos espaços de formação. Sem sua presença protagônica e sua postura dialogante, os espaços de formação agonizam, verdadeiros elefantes brancos por onde não transitam pessoas, atores sociais, professores em relação de ajuda e aprendizagem mútuas e interprofissionais. 
Segundo Cunha (2008), os lugares são preenchidos por subjetividades. É nesse sentido que os espaços vão se constituindo lentamente como lugares "passando a ser dotados de valores e inserindo-se na geografia social de um grupo, que passa a percebê-los como sua base, sua expressão..." (LOPES, 2007, p. 77 apud CUNHA, 2008, p. 185).

Pela presença das pessoas, o espaço se transforma em lugar, ponto de encontro social onde se constrói identidade e reciprocidade.

Uma vida dedicada à procura da identidade é cheia de som e de fúria. "Identidade" significa aparecer: ser diferente e, por essa diferença, singular - e assim a procura da identidade não pode deixar de dividir e separar. E no entanto a vulnerabilidade das identidades individuais e a precariedade da solidária construção da identidade levam os construtores da identidade a procurar cabides em que possam, em conjunto, pendurar seus medos e ansiedades individualmente experimentados e, depois disso, realizar os ritos de exorcismo em companhia de outros indivíduos também assustados e ansiosos. É discutível se essas "comunidades-cabide" oferecem o que se espera que ofereçam - um seguro coletivo contra incertezas individualmente enfrentadas; mas sem dúvida marchar ombro a ombro ao longo de uma ou duas ruas, montar barricadas na companhia de outros ou roçar os cotovelos em trincheiras lotadas, isso pode fornecer um momento de alívio da solidão (BAUMAN, 2003, p. 21).

Uma vez mais buscamos em Cunha (2008) apoio para realçar o caráter solitário do fazer-se professor universitário. Dada a complexidade do trabalho, cresce a necessidade de encontrar e fortalecer alianças. Cresce a importância do coletivo, de uma comunidade que junta aprende a ensinar e a aprender.

Considerando que o sinergismo das forças alinhadas com uma docência socialmente pertinente é favorecido nos lugares da formação construídos processualmente, entendemos que lugares ocupados podem vir a ser territórios.

Lopes (2007, p. 80 apud CUNHA, 2008, p. 185) afirma que "o território é, assim, um espaço mediado pelas representações construídas por um determinado grupo ao estabelecer seu poder frente a outro e que se apropria do espaço como forma de sua expressão e projeção". Nessa explicitação, Cunha (2008) refere que é possível perceber a relação entre espaço, lugar e território. Para a autora, "O espaço se transforma em lugar quando os sujeitos que nele transitam lhe atribuem significados. O lugar se torna território quando se explicitam os valores e dispositivos de poder de quem atribui os significados" (CUNHA, 2008, p. 185).

Para Bauman (2005, p. 47), "sempre há um número demasiado deles. 
'Eles' são os sujeitos dos quais devia haver menos, ou melhor ainda, nenhum. E nunca há um número suficiente de nós. 'Nós' são as pessoas as quais devia haver mais". No caso da pedagogia universitária, temos que nos posicionar mais claramente a respeito de como nos comportaremos diante de um conjunto de profissionais que se tornam professores sem que, na maior parte das vezes, tenham tido sequer uma aproximação dos saberes pedagógicos que constituem a profissionalidade docente em desenvolvimento. Deverão de modo solitário enfrentar este desafio? ("ou nada ou afunda") ou poderão se beneficiar de uma rede de apoio efetiva (encontro com sujeitos, como nós, dos quais deveria haver mais) favorecidos pela criação de espaços - lugares institucionais empenhados em construir uma docência socialmente implicada?

Disso deriva nosso posicionamento acerca das necessidades formativas dos docentes. Sentidas, desejadas ou emergentes? Pensadas a partir de interesses próprios ou interesses imbricados no projeto pedagógico do curso? Interesses induzidos pelas políticas de avaliação externa ou ordenadores de novas posturas dialogantes e interpeladoras da realidade social a servir como balizamento para a formação superior?

\section{Um olhar para o ensino de graduação implicado com a qualida- de social: interpelando políticas institucionais em contextos que requerem tomadas de posição}

Programas institucionais de apoio à inovação pedagógica e curricular deveriam definir/avaliar suas metas e prioridades em uma perspectiva longitudinal e para tanto necessitam não sofrer descontinuidades nas grandes linhas programáticas que os definem e que não podem oscilar ao sabor de cada mudança de reitoria. Aperfeiçoamentos são sempre benéficos nas políticas de formação, mas excesso de mudanças pode servir mais à não mudança, desestabilizando os lugares da formação em construção que podem voltar a se comportar como espaços, ocupados por tempo determinado a partir de lógicas nem sempre compartilhadas lembrando enormes recomeços. Desse modo, precisamos

Entender a profissão docente como um espetáculo que precisa de preparação, ensaio, improviso, atuação - como uma peça de teatro que não é unilateral e tampouco linear - e, ainda, assumirmos que precisamos construir uma cultura de trabalho coletivo pode ser um caminho 
em potencial para que o espetáculo aconteça de forma cada vez melhor! (MARIANO, 2006, p. 26).

Neste sentido, continuidade difere de continuísmo. Importa levar em conta que a historicidade dos programas revela muito a disposição das forças sociais que lutam por um ensino de graduação marcado pelo compromisso com a formação humana e esta luta é constantemente ameaçada pelos interesses mercadológicos que têm penetrado na educação superior e que buscam apequenar a concepção de qualidade dos cursos. Em nome desta "inovação" conservadora, introduzem os recursos tecnológicos como signos do avanço pedagógico; defendem métodos ativos como estratégia motivacional para estudantes desinteressados subvertendo suas potencialidades como recursos para o cultivo do pensar crítico e multidimensional; confundem experiências de internacionalização como possibilidade de aprender com os outros a fazer o certo, subtraindo as oportunidades de trocas multiculturais nas quais se aprende e se ensina, diminuindo o viés colonialista que não combina com nosso projeto de nação.

Enfim, há que ter cuidado sempre, em especial quando nos deparamos com soluções pedagógicas para a formação do docente universitário que subestimam as experiências locais, substituindo-as pela aplicação daquelas que parecem funcionar em outras realidades bastante díspares da nossa conjuntura, cada vez mais iníqua e desigual.

E este é o sentido destas considerações que nos lembram a importância da preservação dos valores e princípios estabelecidos nos programas institucionais de apoio pedagógico aos docentes, ingressantes e/ou iniciantes, nos cursos de graduação de nossas IES. Isso envolve também um olhar para os docentes já em exercício para que possam repensar suas opções pedagógicas à luz das Diretrizes Curriculares Nacionais (DCN) e dos contornos do projeto educativo dos cursos em que atuam.

Tempos difíceis nos espreitam e exigem que os professores universitários voltem a lutar por um lugar de formação substantivamente forte, em que possam se encontrar e juntos aprenderem a ensinar as novas gerações de profissionais cidadãos.

Certa teimosia lhes será exigida dada à complexidade do cenário, mas é neste tempo histórico que lhes cabe atuar. Tempos de políticas de avaliação marcadas pelo imediatismo de resultados estampados em notas obtidas pelos estudantes. Tempos em que docência de qualidade é confundida com número de publicações em periódicos de excelência e parcerias internacionais, nem sempre alinhadas com a complexidade dos problemas locais que precisamos ajudar a equacionar em nome da justiça social. 
Buscamos neste texto defender a ideia de que programas de apoio ao desenvolvimento do docente universitário são essenciais para subsidiar momentos de iniciação à docência que ultrapassem prescrições ligadas ao como fazer uma boa aula, remetendo o foco para aspectos mais substantivos que antecedem às microdecisões pedagógicas informando concepções de Mundo, Homem, Educação que as justificam.

Salientamos a salutar recuperação da categoria da avaliação como promotora de reflexões junto aos docentes sobre um agir pedagógico situado historicamente e preocupado com as consequências edificantes de suas escolhas. A utilização de instâncias de apoio ao desenvolvimento dos docentes universitários deve vir a ser lugares da formação. Lugares que comportam, possibilitam e promovem exercícios de autoconhecimento nos quais os docentes podem, individual e coletivamente, pensar formas alternativas de atuação no ensino de graduação em tempos regidos pelo gerencialismo e pela performatividade (BALL, 2005), podem construir de modo solidário novos processos de trabalho que se embasem nos princípios de uma responsabilização participativa e horizontalizada (SORDI; FREITAS, 2013), garantidores simultaneamente de acolhimento e de estímulo à implicação com um fazer docente contestador de políticas de regulação externa orientadas pelo viés mercadológico. Tais lugares ajudam, assim, a materializar uma pedagogia universitária comprometida com uma formação profissional edificante sob o ponto de vista social.

\section{REFERÊNCIAS}

BALL, S. J. Profissionalismo, gerencialismo e performatividade. Cadernos de Pesquisa, São Paulo, v. 35, n. 126, p. 539-564, set./dez. 2005.

BAUMAN, Z. Comunidade: a busca por segurança no mundo atual. Rio de Janeiro: Jorge Zahar Ed., 2003.

BAUMAN, Z. Vidas desperdiçadas. Rio de Janeiro: Jorge Zahar Ed., 2005.

BENEDITO, V.; IMBERNÓN, F.; FÉLEZ, B. Necesidades y propuestas de formación del profesorado novel de la Universidad de Barcelona. Profesorado. Revista de Currículum y Formación de Profesorado, vol. 5, núm. 2. Universidad de Granada, España, 2001.

BOZU, Z. El profesorado universitario novel y su proceso de inducción profesional. Magis: Revista Internacional de Investigación en Educación. v.1 n. 2. p. 317-328. Bogotá, Colombia, Enero/Junio de 2009. 
COELHO, E. A. D. Docência no ensino superior: dilemas e desafios do professor iniciante. Dissertação (Mestrado em Educação), Universidade Estadual de Londrina, Londrina, 2009.

CUNHA, M. I. Os conceitos de espaço, lugar e território nos processos analíticos da formação dos docentes universitários. Educação Unisinos, v. 12, n. 3, p. 182-186, 2008.

ENGEL, E. P. J. O profissional liberal no início da carreira docente: seus desafios na constituição e na formação da docência universitária. Dissertação (Mestrado em Educação), Universidade do Extremo Sul Catarinense, Criciúma, 2014.

ESCUDERO, J. M.; BOTIA, B. Inovação e formação centrada na escola. Uma perspectiva da realidade espanhola. In: AMIGUINHO, A.; CANÁRIO, R. (Orgs.). Escolas e mudança: O papel dos Centros de Formação. Lisboa: Educa, 1994.

FEIXAS, M. El Profesorado novel: estudio de su problemática en la Universidad Autónoma de Barcelona. Boletín de la RED-U, Santiago de Compostela, v 2, n. 1, p. 33-44, 2002.

FONDÓN, I.; MADERO, M. J.; SARMIENTO, A. Principales Problemas de los Profesores Principiantes en la Enseñanza Universitaria. Form. Univ., La Serena, v. 3, n. 2, 2010.

FREITAS, L. C. et al. Avaliação Educacional: caminhando pela contramão. PetrópolisRJ: Vozes, 2009.

FRIGOTTO, G. A formação e profissionalização do educador: novos desafios. In: SILVA, T. T.; GENTILI, P. Escola S. A. quem ganha e quem perde no mercado educacional do neoliberalismo. CNTE, Brasília, 1996.

GONÇALLO, R. L. A. O professor universitário iniciante: desafios e necessidades no cotidiano da docência. Dissertação (Mestrado em Educação), Universidade Federal do Triângulo Mineiro, Uberaba, 2017.

HEES, L. W. B. O início da docência de professores da educação superior. Tese (Doutorado em Educação: Psicologia da Educação), Pontifícia Universidade Católica de São Paulo, 2016.

HUBERMAN, M. O ciclo de vida profissional dos professores. In: NÓVOA, A. (Org.). Vidas de Professores. Porto: Porto Editora, 1992.

LIMA, E. F. Análise de necessidades formativas de docentes ingressantes numa universidade pública. Revista Brasileira de Estudos Pedagógicos (online), Brasília, v. 96, n. 243, p. 343-358, 2015.

LOPES, J. J. M. Reminiscências na paisagem: vozes, discursos e materialidades na configuração das escolas na produção do espaço brasileiro. In: LOPES, J. J. M.; CLARETO, S. M. (Orgs.). Espaço e Educação: travessias e atravessamentos. Araraquara, Junqueira \& Marin, 2007. p. 73-98.

MARCELO GARCIA, C. Formação de Professores: para uma mudança educativa. Porto: Porto Editora, 1999. 
MARIANO, A. L. S. O início da docência e o espetáculo da vida na escola: abrem-se as cortinas... In: LIMA, E. F. (Org.). Sobrevivências no início da docência. Brasília: Líber Livro, 2006. p. 17-26.

MAYOR RUIZ, C. El desafío de los profesores principiantes universitarios ante su formación. In: MARCELO GARCIA, C. (Org). El profesorado principiante: Inserción a la docencia. Barcelona: Octaedro, 2009.

MAYOR RUIZ, C.; SÁNCHEZ MORENO, M. El Reto de la formación de los docentes universitarios: una experiencia con profesores noveles. Universidad de Sevilla, 2000.

RIVAS, N. P. P.; CONTE, K. M.; AGUILAR, G. M. Novos espaços formativos na universidade: desafios e perspectivas para a docência superior. In: Congresso Estadual Paulista sobre Formação de Educadores, 9, 2007. Textos e Resumos. São Paulo: Pró-Reitoria de Graduação, 2007. p. 2-11.

RODRIGUES, A.; ESTEVES, M. A análise de necessidades na formação de professores. Porto: Porto editora, 1993.

ROSA, C. A. S. Professores iniciantes no ensino superior: um estudo com professores que ensinam Matemática nos Cursos de Licenciatura e Pedagogia. Dissertação (Mestrado em Educação: Psicologia da Educação), Pontifícia Universidade Católica de São Paulo, São Paulo, 2015.

SILVA, V. L. R. Docentes universitários em construção: narrativas de professores iniciantes de uma universidade pública no contexto de sua interiorização no sul do Amazonas. Tese (Doutorado em Educação), Universidade do Vale do Rio dos Sinos, São Leopoldo, 2015.

SORDI, M. R. L.; FREITAS, L. C. Responsabilização participativa. Revista Retratos da Escola, Brasília, v. 7, n. 12, p. 87-99, jan./jun. 2013.

SOUSA SANTOS, B. Um discurso sobre as ciências. 5. ed. São Paulo: Cortez, 2008.

VEIGA, I. P. A. A aventura de formar professores. Campinas, SP: Papirus, 2009.

WIEBUSCH. A. Aprendizagem docente no ensino superior: Desafios e enfrentamentos no trabalho pedagógico do professor iniciante. Dissertação (Mestrado em Educação), Universidade Federal de Santa Maria, Santa Maria, 2016.

ZANCHET, B. M. B. A. et al. Docentes universitários iniciantes: contextos, motivações e experiências. In: CUNHA, M. I. (Org.). Qualidade da graduação: a relação entre ensino, pesquisa e extensão e o desenvolvimento profissional docente. Araraquara, SP: Junqueira \& Marin, 2012.

Texto recebido em 23 de maio de 2019.

Texto aprovado em 29 de maio de 2019. 